\title{
DIOSES GRECORROMANOS EN LAS CRÓNICAS DE INDIAS. LA MITOLOGÍA CLÁSICA EN LA COMPRENSIÓN DEL NUEVO MUNDO
}

\author{
Carolina Valenzuela Matus \\ Universidad Autónoma de Chile \\ carolina.valenzuela01@uautonoma.cl
}

\section{RESUMEN}

La tradición clásica ha contribuido a consolidar nuevos enfoques historiográficos sobre la América hispana. En este artículo, analizaremos, desde esta tradición, la influencia de la mitología grecolatina en las crónicas escritas por tres autores del siglo xvi: Bernardino de Sahagún, Jerónimo de Mendieta y José de Acosta. Estos religiosos compararon en sus obras a los dioses y héroes grecorromanos con los dioses nativos americanos con el objetivo de acercar a sus lectores a la comprensión del conjunto de creencias de estos pueblos a partir del referente familiar de la mitología clásica, especialmente durante el Renacimiento. Con esto, se busca en parte la comprensión del 'otro', pero nunca se pierde de vista el uso de lo clásico como una herramienta para legitimar la conversión y expansión de la evangelización del continente.

Palabras clave: cronistas de Indias, evangelizadores, Nuevo Mundo, tradición clásica.

\section{GRECO-ROMAN GODS IN THE CHRONICLES OF THE INDIES. CLASSICAL MYTHOLOGY IN THE UNDERSTANDING OF THE NEW WORLD}

\section{Abstract}

The classical tradition has contributed to consolidate new historiographic perspectives in the history of the Americas. In this article, we analyze since this tradition the influence of the Greek and Latin mythology in the chroniclers written by three xvi Century churchmen: Bernardino de Sahagún, Jerónimo de Mendieta and José de Acosta. In their works, the comparison of the Graeco-roman gods and heroes with the gods of the natives had the purpose to bring closer to the readers the comprehension of these beliefs considering the classical mythology as a familiar reference, especially during Renaissance. The objective is the comprehension of the 'otherness'. In addition, the classical is still a useful mean to facilitate conversion and legitimate the evangelization of the continent.

Keywords: Chroniclers of Indies, evangelizers, New World, classical tradition. 


\section{INTRODUCCIÓN}

Desde hace algunas décadas, los estudios sobre la tradición clásica proponen nuevas reflexiones sobre las formas de recepción del legado grecolatino en Hispanoamérica desde una perspectiva que entremezcla los aportes de diversas disciplinas como la filología, el arte, la historia, la filosofía, la antropología y la arqueología. El interés que suscitan estos estudios ha permitido que, en pleno siglo xxI, el legado de la tradición clásica siga más vigente que nunca.

Resulta de especial interés comprender, en términos generales, qué entendemos por legado clásico y cómo se visualiza este legado en la historia de América hispana. De acuerdo con Francisco García Jurado (2016), pueden reconocerse cuatro metáforas que contribuyen a las distintas formas que toma la tradición clásica. La primera sería la metáfora hereditaria de la entrega, donde lo clásico es entendido como algo transmisible o legable de una generación a otra, una tradición que discurre desde el pasado hasta el presente. Una segunda metáfora es la de la inmortalidad, y se refiere a la supervivencia del mundo clásico a través de los siglos, que puede trascender de manera ininterrumpida o bien revivir después de un tiempo. La tercera metáfora es la del contagio, que supone un influjo que discurre en un sentido único, desde el autor más antiguo al más reciente y, por último, la metáfora democrática, donde los lectores de otras épocas realizan nuevas lecturas o recepciones de los clásicos motivadas por diversas circunstancias históricas que permiten crear nuevos sentidos, de allí que los clásicos puedan mantenerse vivos en nuestra sociedad contemporánea.

Para el caso de los cronistas de Indias, es observable cómo muchos de estos escritores fueron influenciados por la lectura de los clásicos grecolatinos en el contexto del Renacimiento (fines del siglo XV y siglo XVI), momento determinante en la revaloración de la Antigüedad clásica en Europa. Esto se manifestó preferentemente a través de la difusión y traducción de textos clásicos, muchos de los cuales habían permanecido ocultos y guardados hasta entonces en diversos monasterios de Europa (Greenblatt 2011) o alojados en las bibliotecas de Constantinopla, zona oriental del Imperio romano e importante centro de conocimiento y circulación de ideas (Reynolds y Wilson 1986). Por otra parte, en la misma ciudad de Roma, se va tomando conciencia de que la Antigüedad, y con ella sus vestigios, se podía confrontar para fundar, con un proceso de imitación y emulación, la nueva Roma (Martín-Esperanza 2018).

En esta etapa se dieron otros importantes procesos como el desarrollo científico y las exploraciones geográficas, que permitieron incorporar al conocimiento de Europa territorios lejanos como África, Asia y América y a los pueblos que habitaban estos continentes, lo que se vio reflejado también en el arte de la época y en el interés por lo novedoso y lo exótico, materializado en la creación de gabinetes de naturaleza que albergaban muestras de naturalia y artificialia procedentes de diversos puntos del globo.

España vivió en esta época la consolidación de la monarquía hispánica y el desarrollo de un importante imperio de ultramar. Por tanto, los clásicos fueron utilizados como referentes artísticos, literarios e históricos para representar simbólicamente su poder reflejado en la comparación de la grandeza y ejemplaridad de los Reyes Católicos con el esplendor del Imperio romano bajo Augusto o la represen- 


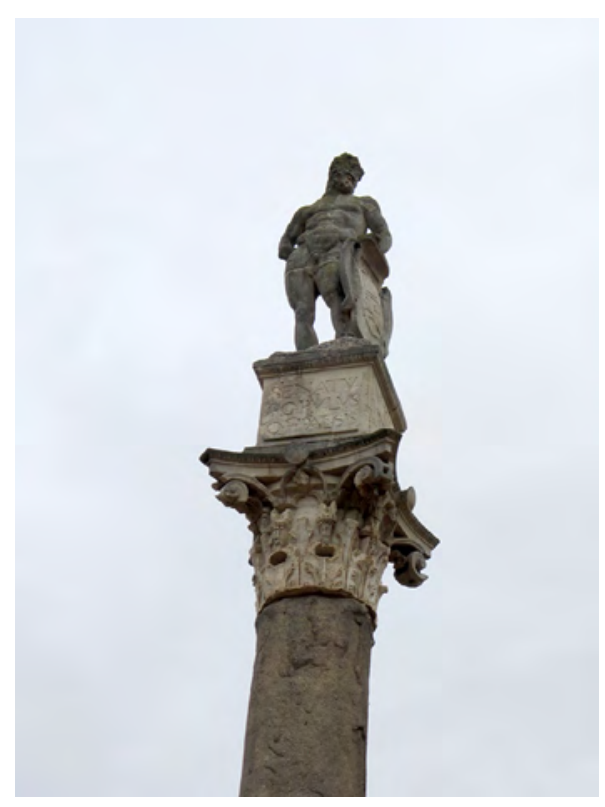

Figura 1. Representación de Carlos V como Hércules. Alameda de Hércules, Sevilla, España. Fotografía de la autora.

tación del emperador Carlos V como un nuevo Hércules (fig. 1) en un momento especialmente floreciente de la expansión geográfica y administrativa de su territorio ultramarino. Los humanistas españoles importaron desde Italia la concepción de un renacer de las letras antiguas y participaron activamente en la misión de recuperar los autores latinos de su país. Se subraya el pasado romano de la Península y se relaciona lo más posible con los romanos, «viendo en Séneca a un compatriota. También intentaron, como Juan de Mena, latinizar el español para demostrar su familiaridad con el latín. Para algunos humanistas como Juan de Lucena, el español estaba incluso más cerca del latín que el italiano» (Biersack 2009).

Con posterioridad a la etapa colonial, en los procesos de independencia de Hispanoamérica se utilizó la estética clásica y también los valores propugnados por esta, para conformar las nuevas naciones. A lo largo de todo el siglo XIX, los clásicos proporcionaron el simbolismo necesario para los ideales de libertad, progreso y civilización en la América hispana difundidos por las nuevas élites políticas y materializados posteriormente en la arquitectura de edificios públicos, estatuarias, discursos, coleccionismo y literatura, entre otros ${ }^{1}$.

1 Véase el más reciente estudio de Ricardo del Molino García, Minerva y los proyectos hispanoamericanos de dominio de la naturaleza en el siglo XIX y principios del siglo XX. El caso de Guate- 
En este artículo analizaremos las influencias clásicas vinculadas a las crónicas de Indias que hemos seleccionado. Sobre estas nos interesa especialmente la influencia de la mitología grecorromana, específicamente a través de sus dioses y héroes. Las crónicas establecieron un paralelo entre estos últimos y los dioses de las culturas nativas con el fin de buscar la comprensión de estas creencias, que muchas veces se contraponían a los tradicionales valores cristianos, pero a partir de modelos ya conocidos por los primeros europeos que llegaron al Nuevo Mundo y en especial por los religiosos dedicados a la evangelización.

\section{CRÓNICAS Y MITOLOGÍA CLÁSICA}

Las crónicas escritas por los diversos conquistadores y evangelizadores españoles que se aventuraron a la conquista de América en el siglo Xvi constituyeron un valioso testimonio de las primeras impresiones y experiencias que los europeos tuvieron en el Nuevo Mundo. Los objetivos que persiguieron estas crónicas fueron muy diversos y no por ello excluyentes; en muchos casos, estuvieron animados por la necesidad de comunicar al monarca lo que sucedía en sus territorios y resaltar así los méritos del cronista en tan arriesgada empresa de ultramar; en otros, se plasmaba la natural curiosidad del ser humano frente a una naturaleza y una población desconocidas para ellos.

En el intento que hicieron los cronistas por acercarse a aquellos aspectos culturales difíciles de comprender para los europeos, utilizaron diversos elementos de la Antigüedad clásica como medio para explicar la vida y las costumbres en las Indias occidentales, entre ellos resulta esencial la mitología, que sirvió para interpretar la religión y a los desconocidos dioses de los nativos a través de patrones ya familiares para la Europa renacentista.

En especial los evangelizadores buscaron en la mitología clásica el punto de acercamiento con las creencias religiosas de los indígenas, y por ello compararon los dioses y mitos de los nativos con los de los antiguos griegos y romanos. Esto es llamado por el antropólogo Fermín del Pino "comparación a efectos compensatorios» nos explica:

Esta comparación entre la religión americana y la de los tiempos clásicos de Europa tiende a compensar el mal efecto que puede producir en el lector europeo la descripción de creencias o ritos extraños, chocantes y a veces horribles (Pino Díaz 1982).

Colocar las creencias religiosas de los nativos al nivel de los clásicos demostraba que estos eran aptos para la cristianización y que sus civilizaciones en nada

mala (1898-1920). Destaca también el proyecto liderado por Mireia Romero titulado «Recepción e influjo de Pompeya y Herculano en España e Iberoamérica». Ministerio de Ciencia, Innovación y Universidades (PGC2018-093509-B-I00). 
desmerecían de las de los antiguos griegos y romanos, quienes volvían a ser un referente de autoridad con el Renacimiento.

La presencia de la mitología clásica en la interpretación de los dioses de los nativos americanos se encuentra de forma abundante en las crónicas, pero por la brevedad de este estudio, analizaremos estas analogías en la obra de tres religiosos: Bernardino de Sahagún, Historia general de las cosas de la Nueva España (c. 1577); Jerónimo de Mendieta, Historia Eclesiástica Indiana (c. 1573-1574); y José de Acosta, Historia Natural y Moral de las Indias (1590). En ellas encontramos ejemplos de cómo los evangelizadores comparan los atributos de los dioses locales con los dioses de la Antigüedad grecorromana. Se busca analizar los casos más significativos, teniendo siempre en perspectiva el hecho de que estos religiosos trabajaron tanto en pos de sus propósitos misionales como en la búsqueda de la comprensión de un otro completamente distinto a lo conocido por ellos hasta ese momento.

2.1. Fray Bernardino de Sahagún (1499-c. 1590): Historia general DE LAS COSAS DE LA NUEVA ESPANA

La Historia general de las cosas de la Nueva España ha sido considerada uno de los mayores antecedentes para el estudio etnográfico de México a pesar de su propósito claramente misional. Su autor, fray Bernardino de Sahagún, estudió en la Universidad de Salamanca, centro importante del Renacimiento europeo en Espańa. Hacia 1527 entró en la orden franciscana y dos años después emprendió su viaje a la Nueva España, en una misión encabezada por fray Antonio de Ciudad Rodrigo. Pasó todo el resto de su vida en México y escribió diversas obras en latín, náhuatl y español. De toda su producción, solo llegó a ver impresa su Psalmodia Christiana y Sermonario de los Santos del año en lengua mexicana (1583). Su obra monumental fue la Historia general de las cosas de la Nueva España, que le tomó más de treinta años de arduo trabajo para nunca verla impresa, ya que la obra se imprimió por primera vez recién en 1829 .

La elaboración de la Historia general fue compleja. En 1570, el trabajo que llevaba haciendo Sahagún junto con sus informantes fue paralizado por falta de fondos y por la escasa ayuda de sus superiores; dos años después, debió asumir la dirección y administración del colegio de Santa Cruz, lo que le dejó poco tiempo para la escritura. En 1575, un decreto real le ordena preparar una versión española de su texto y enviarla a España. No obstante, en 1577, el rey Felipe II emitió un decreto prohibiendo toda nueva investigación de la historia y religión de los naturales (Brading 1991), acontecimiento que condenó su obra a permanecer manuscrita. En México, «el virrey Martín Enríquez trató de adueñarse de los manuscritos de Sahagún, privando así al anciano de toda esperanza de ver algún día impresa la obra de su vida» (Brading 1991).

Una de las características de esta obra fue la complejidad de sus manuscritos debido a la existencia de varias copias de una misma obra en etapas distintas de su elaboración, el estado fragmentario de algunas de ellas y el frecuente cambio de títulos y arreglos. Para Ballesteros, la obra de Sahagún pasaría por tres periodos: 
1. Conocimiento por unos y por otros, incautaciones, envíos a España y dispersión. Algunas partes de la obra manuscrita fueron aprovechadas, con cita o sin ella, por varios autores (siglo XVI y comienzo del XVII). 2. Olvido total y custodia inconsciente en las bibliotecas y archivos a donde habían ido a parar los manuscritos (siglo Xviı y primera mitad del siglo XVIII). 3. Descubrimiento de los manuscritos, valoración de los mismos, copia de uno y otros y comienzo y aumento de las ediciones (segunda mitad los siglos XVIII, xIX y xx) (Ballesteros 1964).

En la obra se reconocen tres códices: el Matritense, el de Tolosa y el Florentino o Sequera. El códice Matritense se compone de la transcripción de los textos en idioma náhuatl compilados por Sahagún. Hacia 1762 una parte fue adquirida por un librero de Madrid y posteriormente vendida una parte a la Biblioteca de la Real Academia de la Historia, y la otra, al Palacio Real. Los libros i y v, que forman parte de estos códices, debieron componerse entre 1569 y 1571. Fueron publicados por Francisco del Paso y Troncoso en 1906. El códice de Tolosa contiene solo el texto en español con algunas variantes. La primera edición, de 1829, estaría basada en este manuscrito conservado en el convento de Tolosa (Navarra) sin que se sepa hasta ahora cómo llegó hasta allí. El códice Florentino o códice Sequera proviene de la obra monumental y manuscrita de Sahagún, que habría sido terminada hacia 1577. Esta obra fue llevada a Espańa por Rodrigo de Sequera en 1580, pero se conserva actualmente en la biblioteca Medicea Laurenziana de esa ciudad (Valenzuela 2016).

Originalmente la obra llevó el título de Historia Universal, título que se perdió con el tiempo dando paso a la denominación de Historia general. El texto en su forma final consistió en dos columnas de texto, una en náhuatl y el otro una «traducción» más o menos libre al castellano y numerosas ilustraciones en la copia más lujosa. Se dividió en doce libros donde se describen los orígenes y atributos de los dioses mexicanos, el calendario, los augurios y sus adivinos, descripciones de los cielos y de la naturaleza, de los reyes y señores, de los discursos moralizantes, así como también de los comerciantes y gente común, concluyendo con oraciones y plegarias y con el relato de la conquista desde la visión de los naturales.

Para David Brading, la obra de Sahagún está lejos de ser una historia, pues es débil al tratar los hechos del pasado, pero sí constituye «una enciclopedia que cubre virtualmente todos los aspectos de la religión, la sociedad y la filosofía natural de los mexicanos» (Brading 1991). Durante su investigación, Sahagún contó con la ayuda de antiguos alumnos suyos del colegio de Santa Cruz de Tlatelolco, quienes, además de conocer la lengua de sus mayores, eran diestros en el manejo del español y el latín.

En la Historia general, se observa claramente que la percepción que tiene el franciscano de la religión de los indígenas está determinada por un paralelismo con los dioses grecorromanos, ya que «para él la religión indígena no es un amasijo informe de supersticiones, sino un verdadero sistema de creencias, como lo fueran en su día el conjunto mitológico greco latino» (Ballesteros 1973). Para Sahagún el paralelo existe y se trata de un conjunto de dioses tan legítimos para los mexicanos como lo fueron los suyos para los hombres de la Antigüedad clásica. Sin embargo, 
que sean considerados legítimos en su contexto no significa que sean tenidos por tales por el franciscano, quien es ante todo un evangelizador comprometido con su causa, que es la implantación de la religión cristiana católica en el Nuevo Mundo. El análisis del legado clásico que aquí se procede a realizar utiliza como base el texto castellano del códice Florentino, en la edición de 1989, preparada por Alfredo López Austin y Josefina García Quintana.

Uno de los primeros aspectos en que se evidencia este legado en la obra lo encontramos en la historia de los primeros pueblos de México. El autor hace referencia a la antigua y célebre ciudad de Tulla, que habría sido destruida hacía ya mil años y que además:

Tuvo la adversa fortuna de Troya. Los chololtecas, que son los que della se escaparon, han tenido la succesión de los romanos, y como los romanos edificaron el Capitolio para su fortaleza, así los chololanos edificaron a mano aquel promontorio que está junto a Cholula. De la manera en que los chololtecas parecen haber tenido la sucesión de Roma, los tlaxcaltecas parecen haber succedido en la fortuna de los cartagineses. Hay grandes señales de las antiguallas destas gentes, como hoy día parece en Tulla y en Tullantzinco, y en un edificio llamado Xuchicalco (Sahagún 1989).

Encontramos también una interesante referencia a una ceremonia realizada en el mes de Izcalli, que es comparada con una práctica propia de la religión romana:

Acabándolos de horadar las orejas [a los niños], llevábanlos los padrinos y madrinas a rodearlos por la llama de un fuego que tenían aparejado para esto, que en latín se dice lustrare, que es ceremonia que la Sagrada Escritura reprende (Sahagún 1989).

Queda claro el conocimiento que Sahagún tenía del lustro, que consistía en una purificación mediante un sacrificio expiatorio, propia de la religión romana. Contreras y otros (1992) explican que se trata de la purificación de las impurezas morales de los hombres, animales y cosas. Esta era realizada por una persona experta y autorizada, distinta a la que era objeto de la ceremonia. Comportaba una serie de ritos que si se cumplían a cabalidad aseguraban que el efecto esperado se diera de forma infalible. Los instrumentos para realizar esta purificación en Roma fueron muy variados, entre ellos encontramos el agua, el fuego, el aire, el laurel, el olivo o la sangre de las víctimas sacrificadas, entre otras. Probablemente, Sahagún encontró alguna vaga similitud entre el rito mexicano que describe y la antigua práctica romana en lo que se refiere a la purificación mediante el fuego.

Asimismo, en la obra de fray Bernardino se encuentran diversos ejemplos de la comparación de los atributos de los dioses locales de México con los dioses de la Antigüedad grecorromana, por ejemplo, el dios Huitzilopuchtli «fue otro Hércules²,

2 Considero interesante señalar un paralelismo en Tácito cuando habla de los germanos señalando: «Recuerdan que entre ellos hubo también un Hércules, y cuando van a combatir lo celebran como el primero de todos los Héroes». Tac. Agr., 3,1. Sin embargo, es difícil identificar las influencias de este autor en Sahagún. 
el cual fue robustísimo, de grandes fuerzas y muy belicoso, gran destruidor de pueblos y matador de gentes» (Sahagún 1989). Del dios Tezcatlipoca dice que es «otro Júpiter», la diosa Chicomecóatl es vista como «otra diosa Ceres» (Sahagún 1989)³. La diosa del agua Chalchiuhtli Icue es «otra Juno» y la diosa de las cosas carnales Tlazultéutl es «otra Venus». Uno de los dioses menores en dignidad, Xiuhtecuhtli, «es otro Vulcán» (Sahagún 1989).

Estos ejemplos confirman el conocimiento que fray Bernardino tiene sobre los textos clásicos, que es lo que permite, según Rodríguez y Castro, que le sea fácil

hallar el paralelismo y la identidad de los dioses greco- romanos con los dioses mexicanos, aun a pesar de que no sabemos se encontrase en la biblioteca del convento de México (Tlatelolco) un libro de mitología greco-latina, los cual nos hace pensar que Fray Bernardino lo llevaba bien aprendido desde España (Rodríguez y Castro 1986).

López Austin observa que en la obra de Sahagún los dioses de los indígenas son de la misma índole que los dioses de los gentiles del Viejo Mundo, lo que queda reafirmado por las comparaciones del libro I. Se piensa también que en Sahagún hay algunas influencias del evemerismo, propio de las creencias de su época: Evémero era un filósofo y viajero griego que vivió entre los siglos III y IV a.C. y que en su obra Escrito Sagrado quiso demostrar que los llamados dioses habían sido en su tiempo seres humanos y que fueron considerados como dignos de culto por las generaciones posteriores (López Austin 2001).

Para López Austin, esta influencia es visible en Sahagún, quien afirmó la existencia humana de muchos de los dioses indígenas. Sahagún pudo haber tenido noticias de Evémero a través de san Agustín, quien lo menciona en el libro vi de La ciudad de Dios ${ }^{4}$, aunque en ninguna parte el religioso lo cita directamente: su influencia ha de buscarse en la cercanía de las ideas, sobre todo en el contexto de la defensa de la religión cristiana frente a los cultos paganos.

En el libro III, Sahagún ve a Quetzalcóatl como otro Hércules (recordemos que en el libro I relaciona a Hércules con Huitzilopochtli), pero no da mayores detalles sobre las características que justifican esta relación. Sobre esta temática resulta de gran interés el artículo de Javier Martínez Villarroya «Quetzalcoatl

\footnotetext{
${ }^{3}$ María José García (1989) señala que tampoco se encuentra tal identificación en el texto náhuatl.

${ }^{4}$ San Agustín decía: «¿Qué concepto tuvieron de Júpiter los que colocaron a su nodriza en el Capitolio? ¿No es cierto que confirmaron el pensamiento de Evémero, quien escribió no con mítica garrulería, sino con solicitud histórica, que todos esos dioses son hombres y seres mortales? Los que sentaron a la mesa de Júpiter a los dioses comilones y parásitos suyos, ¿qué pretendieron sino convertir lo sagrado en bufonesco?». Agustín, Civ., vi, 7, 251. Para Gilbert Highet: «Evémero explicaba todas las leyendas -divinas, humanas y semihumanas- diciendo que eran versiones ennoblecidas de las hazañas de guerreros y caudillos de carne y hueso que habían vivido mucho tiempo atrás, y que habían sido transformados en dioses por la admiración de sus tribus». Véase Highet 1996.
} 
y Heracles», donde se analizan en profundidad las analogías de estos mitos, señalando entre otras cosas:

Tanto Heracles como Quetzalcoatl son reyes expulsados de sus reinos, que en peregrinación se dirigen al País del Sol. Ambos reciben sacrificios de niños, civilizan pueblos y se debaten entre las dos vías, la del asceta y la del vividor. Su viaje a los infiernos se debe a que unen el cielo y la tierra, el espíritu y la materia, como fieles representantes de la realeza divina (Martínez 2005).

Efectivamente se pueden observar estas características en la obra del religioso: Sahagún relata que Quetzalcóatl se ve obligado a salir de la antigua ciudad de Tulla por engaño de unos nigrománticos. En su camino hacia la ciudad de Tlapalla, al igual que Hércules, fue viviendo varias aventuras como nos cuenta el propio religioso: «Hay otras cosas notables que hizo el Quetzalcóatl en muchos pueblos y dio todos los nombres a las sierras y montes y lugares» (Sahagún 1989).

A través de estas analogías existentes entre los dioses de los indios y las divinidades grecorromanas, Sahagún elabora un trabajo etnohistórico que aproxima a sus lectores a los antiguos dioses mexicanos y sobre todo a las creencias religiosas de estos pueblos, que han de ser conocidas para poder lograr la expansión de la fe cristiana.

\subsection{Fray Jerónimo de Mendieta (1525-1604): Historia ECLesiástica Indiana}

Fray Jerónimo de Mendieta fue también un religioso franciscano considerado uno de los últimos testigos de la edad dorada del siglo xvi. Como resultó común en su época, su máxima obra, Historia Eclesiástica Indiana, no llegó a imprimirse. La obra desapareció y solo se conoció su contenido parcial a través de la obra de fray Juan de Torquemada Monarquía indiana (1615). La Historia Eclesiástica de Mendieta se consideró perdida durante mucho tiempo hasta que el historiador y bibliógrafo español Pascual de Guayangos la encontró en la biblioteca del erudito y escritor Bartolomé José Gallardo. Por Guayangos la obra llegó al historiador mexicano Joaquín García Icazbalzeta, quien la publicó en 1874 (Valenzuela 2014). Su redescubrimiento a fines del siglo XIX resultó esencial para ampliar el conocimiento de los métodos misionales aplicados en el Nuevo Mundo.

Fray Jerónimo de Mendieta ingresó a la orden franciscana en 1545. En 1554 se trasladó a México para realizar labores de evangelización. Volvió a la península Ibérica en 1570, pero tres años después regresó a América de forma definitiva, tiempo en el que escribió la Historia Eclesiástica Indiana. En su obra, el religioso alaba las buenas condiciones de los nativos para recibir la palabra de Dios. Para Martínez Ferrer, Mendieta descubre en los naturales prehispánicos «valores religiosos auténticos, que conectan con lo mejor de la religiosidad y moral de los paganos clásicos como Aristóteles o Virgilio» (Martínez Ferrer 2008). Insiste en que originalmente los indígenas fueron monoteístas, tuvieron el conocimiento de un único y verdadero Dios, y que solo cayeron en el politeísmo como engaño del demonio. Asegurando este antecedente, los religiosos se convencían aún más de que los indígenas tenían todas las condiciones para adoptar sin problemas la religión cristiana. 
Pese a su marcado carácter milenarista que veía la proximidad del fin del mundo y la llegada de una nueva era, Mendieta no se mantiene ajeno al humanismo del siglo XVI, ya que los intereses misionales de los franciscanos lograron establecer una destacada conexión con el mundo clásico. En Sahagún, la América precolombina y la Antigüedad clásica funcionan como periodos análogos, esto significa que se buscan las similitudes entre la conversión de los indios del Nuevo Mundo llevada a cabo por estos evangelizadores con la conversión de los gentiles de la Antigüedad clásica (Phelan 1972).

En este breve análisis, utilizamos la edición de la Historia Eclesiástica Indiana de 1973, perteneciente a la Biblioteca de Autores Españoles (BAE). En la obra podemos constatar que, al igual que Sahagún, Mendieta trata de explicar la religión de los indios de la Nueva España recurriendo a ejemplos del mundo clásico y también a los escritos de Aristóteles y Virgilio. Luis Martínez Ferrer señala que las referencias a estos autores permiten interpretar con cierto realismo y «cientificidad» la religión prehispánica (Martínez Ferrer 2008), sobre todo cuando busca similitudes entre las creencias de los antiguos con los nativos del Nuevo Mundo:

Y así en lo primero conformaban con los gentiles antiguos, que a las ánimas de buenos y malos hacían moradores del infierno, como lo cuenta Virgilio en sus Eneidos, escribiendo la bajada de Eneas a aquel lugar (Mendieta 1973).

Mendieta continúa la comparación de las creencias de los nativos con el mundo cristiano, ya que señala que para ellos la medida de los castigos se aplica de acuerdo a la magnitud del pecado, y sobre este punto habría similitud entre los naturales de Indias, los antiguos griegos y los actuales cristianos.

Allí se refieren la diversidad de tormentos que vio Eneas, y por el consiguiente conforman con nosotros los cristianos que tenemos por fe lo que en diversas partes de la Escritura Sagrada se dice: que según la medida del pecado, será la manera de las llagas (Mendieta 1973).

En materia de los dioses, el que parece disgustar menos a Mendieta es Quetzalcóatl, quien ocupa un lugar principal en el conjunto de las creencias religiosas y que era reverenciado por tres cosas; primero, porque enseñó el oficio de la platería; segundo, por no admitir sacrificios de sangre; y tercero, porque vedaba y prohibía con eficacia la guerra, robos, muertes y otros daños. Posiblemente, se podría hacer más tolerable por el hecho de que a él no iban asociados los tan deplorables sacrificios humanos que tanto excitaron la imaginación de los religiosos y de los conquistadores en general (fig. 2).

En otro aspecto, reconoce que nahuas y otomíes tenían sus propias creencias sobre la vida y la muerte, contando que a los que morían de enfermedad «un perro bermejo los hacía pasar un río muy ancho, donde quedaban para siempre: que alude a la de la laguna Estigia, y al can Cerbero de nuestros antiguos gentiles» (Mendieta 1973).

Un uso similar de la Antigüedad se encuentra más adelante cuando relata que un sacerdote de los ídolos se vistió como el dios del vino. 


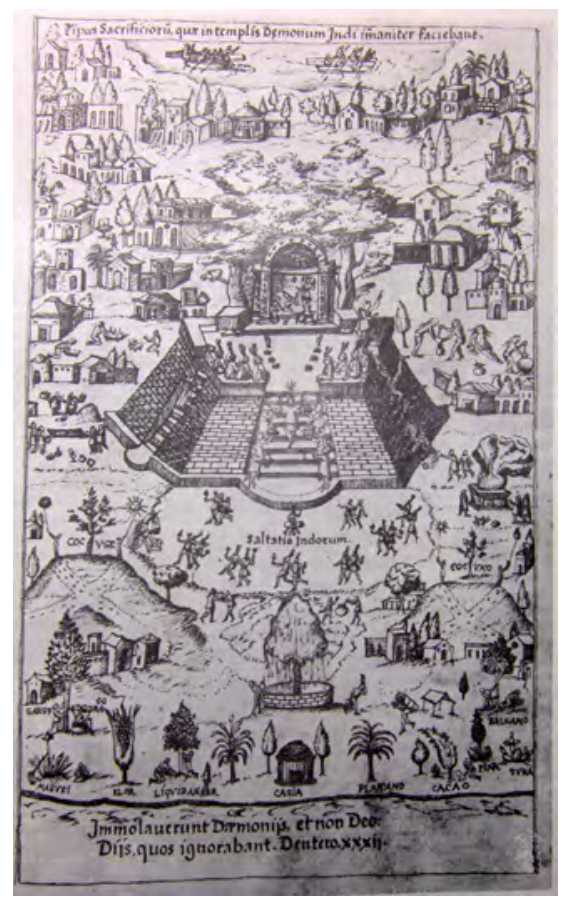

Figura 2. Representación de los sacrificios indígenas en Jerónimo de Mendieta, Historia Eclesiástica Indiana, edición de 1973, libro II, p. 50.

Quiso uno de ellos hacer demostración ante el pueblo, para que entendiese la gente que no había que temer al Dios de los cristianos ni a sus predicadores y para esto vistióse de las insignias de un dios que ellos tenían, llamado Ometochtli, que decían ser el dios del vino (como otro Baco), y salió al mercado mostrándose muy feroz y espantable (Mendieta 1973).

En la obra, Ometochtli es puesto en relación con Baco y aquel que se disfrazó del dios del vino murió debido al ataque de la gente del pueblo. Encontramos en la obra de Mendieta ejemplos concretos sobre la comparación de los dioses nativos con los de la Antigüedad grecorromana, logrando identificar en un autor de marcada influencia milenarista ${ }^{5}$ importantes valores de la tradición clásica. Por

5 Mendieta apostaba por mantener una Iglesia primitiva en las Indias, por lo que era necesaria la segregación de las comunidades indígenas como una condición para la creación de un reino milenario, como se ha señalado anteriormente. Por ello dedicó importante tiempo y energía en convencer a las autoridades de la necesidad de proteger a los indígenas (Valenzuela 2016). Los milenaristas creían que Cristo volvería a reinar sobre la tierra durante mil ańos, antes del último 
ello, se han de considerar ambas vertientes en los nuevos análisis que aborden la obra de este franciscano.

\subsection{JosÉ de Acosta (1540-1600): Historia NATURAL Y MORAL DE LAS INDIAS}

La Historia Natural y Moral de las Indias del jesuita José de Acosta, ha sido un referente para el estudio de la historia y de la antropología del Nuevo Mundo, convirtiéndose en un libro trascendente para el conocimiento de la naturaleza y la geografía, así como del pasado y las costumbres indígenas. Su obra constituyó todo un referente posterior en la elaboración de las historias naturales jesuitas realizadas por destacados intelectuales como Francisco Xavier Clavigero, Bernabé Cobo, Juan de Velasco o Juan Ignacio Molina (Valenzuela 2018).

José de Acosta, procedente de Medina del Campo, ingresó muy joven a la Compañía de Jesús. Realizó estudios en Alcalá de Henares, reconocido centro humanista español de la época. Se desempeñó como profesor en diversas residencias de la Compañía en España y en 1571 llegó a América para establecerse en el Virreinato del Perú, desde donde realizó diversos viajes con fines misioneros. En 1586 viajó hacia Nueva España, donde permaneció casi un año para luego regresar a España. En 1588 salía impreso en Salamanca su primer libro, De Procuranda Indorum Salute, precedido del De Natura Novi Orbis. De la traducción al castellano de este último surgirían los dos primeros libros para su Historia Natural y Moral de las Indias (1590), dedicada a la infanta Isabel Clara Eugenia, hija del rey Felipe II. En Roma, imprimió algunas obras en latín: De Christo Revelato libri Novem y De Temporibus Novissimus Libri Quatuor. En este sentido, Acosta fue más afortunado que Bernardino de Sahagún y Jerónimo de Mendieta porque pudo ver publicada su obra en vida y con una muy amplia difusión, ya que al año siguiente de su primera publicación se editó también en Barcelona, fue traducida en 1596 al italiano, en 1598 al holandés y francés, en 1601 al alemán y en 1604 al inglés (Marroquín 2019). La edición que utilizamos en este análisis corresponde a la de 2008, realizada por Fermín del Pino Díaz.

En la Historia Natural y Moral de las Indias, las principales alusiones a los dioses indígenas y su comparación con los dioses grecolatinos las encontramos en la parte correspondiente a la historia moral, que hace referencia a las tradiciones y costumbres de los nativos, específicamente en el libro v, donde explica en qué consistían los dioses adorados por los indígenas del Perú:

combate contra el mal, para comenzar así el Juicio Universal. Este pensamiento se extendió especialmente durante la Edad Media, pero también tuvo influencias posteriores, como lo demuestra la obra de Jerónimo de Mendieta o posteriormente, el jesuita chileno Manuel Lacunza con su obra La venida del Mesías en Gloria y Majestad (1790). El libro de Lacunza fue incluido en el índice de libros prohibidos por la Inquisición. 
También adoraban a la tierra, que llamaban Pachamama, al modo que los antiguos celebraban la diosa Tellus; y al mar, que llamaban Mamacocha, como los antiguos a la Tetis o al Neptuno (Acosta 2008).

Al comparar la religión de los pueblos de México con la de los indígenas del Perú, Acosta considera que la idolatría de los mexicanos fue más errada y perniciosa que la de los incas porque

la mayor parte de su adoración e idolatría se ocupaba en los ídolos y no en las mismas cosas naturales, aunque a los ídolos se les atribuía estos efectos naturales, como del llover y del ganado, de la guerra, de la generación, como los griegos y latinos pusieron también ídolos de Febo, y de Mercurio, y de Júpiter, y de Minerva, y de Marte, etc. (Acosta 2008).

Para Acosta la religión de los peruanos puede bien compararse con la romana, al relacionar un templo del Perú con el Panteón de los romanos, ya que se trataba de la casa y morada de todos los dioses, al encontrarse allí los dioses de todas las provincias, incluso de aquellos lugares conquistados:

Otro templo y adoratorio aún muy principal hubo en el Perú, que fue en la ciudad del Cuzco, donde es agora el monasterio de Santo Domingo, y en los sillares y piedras del edificio, que hoy día permanecen, se echa de ver que fuese cosa muy principal. Era este templo como el Panteón de los romanos, cuanto a ser casa y morada de todos los dioses. Porque en ella pusieron los reyes Ingas los dioses de todas las provincias y gentes que conquistaron, estando cada ídolo en su particular asiento y haciéndole culto y veneración los de su provincia con un gasto excesivo de cosas que se traían para su ministerio, y con esto les parecía que tenían seguras las provincias ganadas, con tener como rehenes sus dioses (Acosta 2008).

A lo largo del libro v se observa que el jesuita no se muestra en absoluto escandalizado con la idolatría de los indígenas, ya que también los antiguos griegos y romanos vivieron en la idolatría según la visión de la época. Sin embargo, hay algunos hechos que le causan gran admiración y que describe con lujo de detalles; ejemplo de ello es lo sucedido en una ceremonia en México, donde se le arrancó el corazón a un joven, estando de testigos varios españoles:

Habiendo abierto y sacado el corazón a un mancebo muy bien dispuesto, y echándole rodando por la escalera abajo como era su costumbre, cuando llegó abajo, dijo el mancebo a los Españoles en su lengua: Caballeros muerto me han (Acosta 2008).

Estos hechos que sorprenden tanto a los conquistadores españoles encuentran respuesta en el razonamiento de José de Acosta citando nuevamente a los clásicos:

Y no es cosa increíble, que aquel hablase habiéndole arrancado el corazón pues refiere Galeno haber sucedido algunas veces en sacrificios de animales, después de haberles sacado el corazón, y echándole en el altar, respirar los tales animales, y aun bramar reciamente, y huir por un rato (Acosta 2008). 

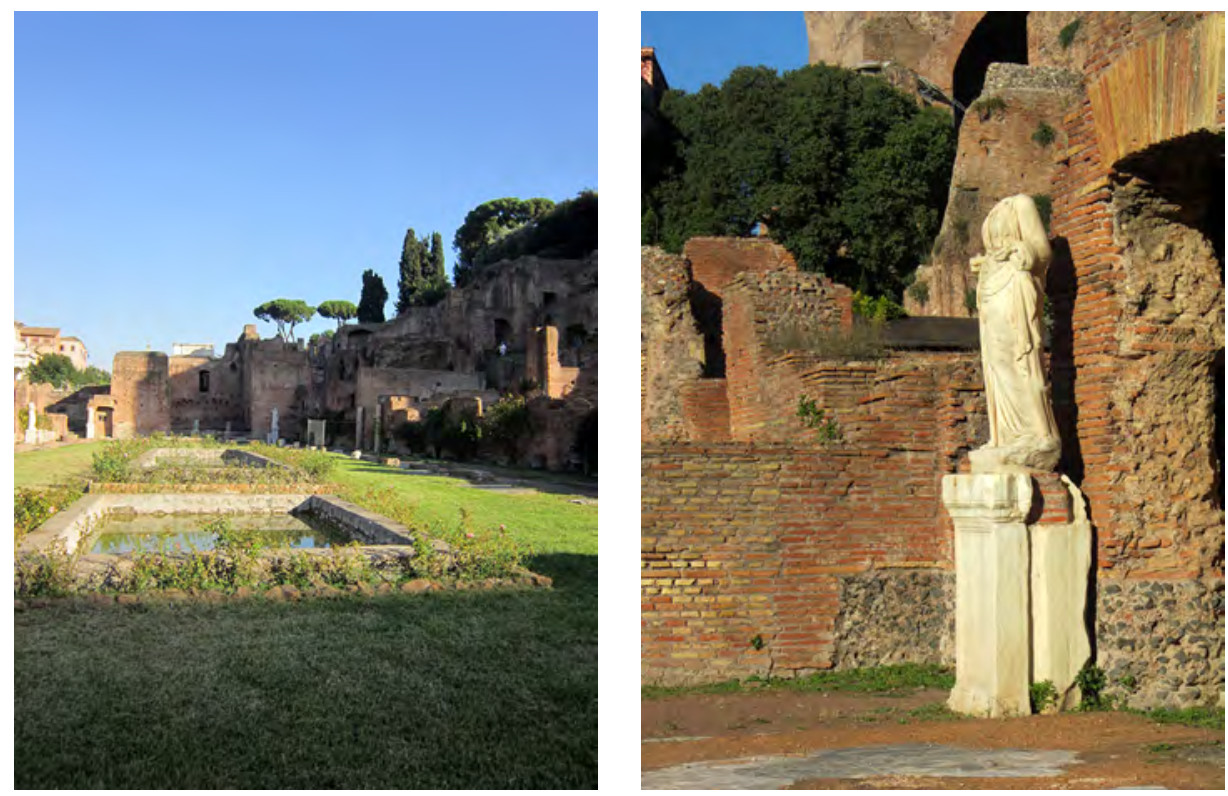

Figuras 3 y 4 . Los conquistadores y evangelizadores vieron un gran parecido entre las acllas del Imperio inca y las vestales de Roma. Imagen de la Casa de las Vestales. Roma. Fotografías de la autora.

Al igual que Sahagún, Acosta también habla de uno de los dioses principales de los mexicanos, Quetzalcóatl, refiriéndose a este como uno de los más venerados en Cholula en su condición de dios de las mercaderías. En este caso, Quetzalcóatl no es comparado con Hércules, sino con Plutón:

Era en figura de hombre, pero la cara de pájaro, con un pico colorado y sobre él una cresta y verrugas, con unas rengleras de dientes y la lengua de fuera. En la cabeza, una mitra de papel puntiaguda pintada; una hoz en la mano y muchos aderezos de oro en las piernas y otras mil invenciones de disparates, que todo aquello significaba y, en efecto, le adoraban porque hacía ricos a los que quería, como el otro dios Mamón, o el otro Plutón (Acosta 2008).

En el siguiente capítulo se refiere al monasterio de vírgenes de Acllaguaci, en el Perú, encontrando semejanza entre estas doncellas y el sacerdocio femenino en México con las vírgenes vestales de Roma referidas por los historiadores (figs. 3 y 4) (Acosta 2008) ${ }^{6}$.

${ }^{6}$ El autor no especifica a cuáles historiadores se refiere, siendo varios los que hacen referencia en sus textos a las sacerdotisas de Vesta, entre ellos Dión Casio, quien nos señala que a ellas se les 
Alguna semejanza tiene lo de estas doncellas, y más lo de las del Perú, con las vírgenes vestales de Roma, que refieren los historiadores, para que se entienda cómo el demonio ha tenido codicia de ser servido de gente que guarda limpieza, no porque a él le agrada la limpieza pues el de suyo espíritu inmundo, sino por quitar al sumo Dios, en el modo que puede esta gloria de servirse de integridad y limpieza (Acosta 2008).

Ciertamente, Acosta tenía referencia de la diosa Vesta, diosa romana del hogar, y de las vírgenes consagradas a su culto, por lo que no duda en comparar a las vírgenes de Acllaguaci con las antiguas vestales. Vemos entonces que Acosta intenta también comprender los atributos de los dioses y las características de la religión de los nativos a través del prisma de la Antigüedad clásica. Para realizar estas comparaciones, Acosta se vale de diversas fuentes, entre ellas resulta importante su propia experiencia personal, que incluía sus navegaciones transatlánticas, su trabajo como visitador, historiador y teólogo en el Perú y su viaje a la Nueva España. También se valió de la consulta a expertos en los temas que le interesaban, y entre estos expertos se encontraron con frecuencia los propios indios americanos (Marroquín 2019).

Acosta también trata en su libro la similitud de los ritos católicos y paganos, sobre todo en lo que él ve en la semejanza con la comunión, y a través de ello busca una amplia descripción sobre sus ceremonias. Se refiere también a la confesión y a los confesores y realiza comparaciones con los ritos del Japón, de los cuales parece estar correctamente informado a través de los miembros de la Compañía que se encuentran en Oriente. Busca asimismo la semejanza de los ritos de los indios con los cristianos y vuelve a insistir en que las idolatrías practicadas en Cuzco o en México son del mismo tipo que en su tiempo se dieron en Roma o en Jerusalén. Describe también las fiestas ordinarias y extraordinarias de los incas y los mexi-

encargó «que tuvieran el cuidado del fuego y del agua» y que "guardaban su virginidad durante su vida y, si no, las enterraban con piedras». Ver, D.C. Historia Romana, 182. También lo hace Suetonio, en su vida de Augusto, comentando que «aumentó el número de sacerdotes, su dignidad y hasta sus privilegios, especialmente los de las vestales. Habiendo fallecido una de éstas se trataba de reemplazarla, y como muchos ciudadanos solicitasen el favor de no someter a sus hijas a los riesgos del sorteo, dijo él que si alguna hija suya hubiese llegado a la edad requerida la hubiese ofrecido espontáneamente». Suet. Aug., 108. También aparecen referencias en la vida de Tiberio Nerón, quien tiene una entre sus antepasados: «Viese asimismo una Claudia, sacerdotisa de Vesta, montar en el carro de su hermano, que iba en triunfo a pesar del pueblo, y acompañarle de este modo hasta el Capitolio, con el objeto de que los tribunos nada pudieran contra él». Suet. Tib., 180. Encontramos también importante referencia en las Cartas de Plinio el Joven: «Estoy muy inquieto por la enfermedad de Fania. La contrajo mientras cuidaba a la vestal Junia, al principio por propia voluntad (pues Junia es pariente suya), luego también por orden de los pontífices. Pues las vírgenes vestales, cuando son obligadas por una grave enfermedad a abandonar el templo de Vesta, son confiadas al cuidado y protección de mujeres casadas». Plin. Ep., 19, 2. También encontramos información en san Agustín en varias partes de La ciudad de Dios, entre ellas citamos: «Pues los antiguos romanos enterraban vivas a las sacerdotisas de Vesta sorprendidas en relaciones ilícitas». Libro III, 5, 216-217, sobre este castigo también da noticia Plin. Ep., Iv, 11, 7. También nos dice san Agustín: «Vesta no es sino el fuego propio de los hogares, sin los cuales la ciudad no puede existir, y que suelen estar a su servicio unas vírgenes...». Libro IV, 10, 293. 
canos, donde es apreciable su labor etnográfica, lo que se contradice con la poca importancia que dice dar a estos temas, tal vez por guardar la debida cautela de no poner el mayor énfasis en materias que habían sido restringidas desde las Ordenanzas de Felipe II en 1577.

Los aspectos comparativos de la religión indígena con la grecorromana son solo uno de los elementos de la influencia clásica en su obra. La influencia clásica en la Historia Natural y Moral es mucho más relevante cuando se tocan aspectos referentes al mundo natural y físico de América. En ellos se identifican claramente las influencias de la Historia Natural de Plinio el Viejo, presentes en los capítulos dedicados a la minería y a la naturaleza, y sobre las que se han desarrollado extensas investigaciones (Salazar 2000, López Gregoris 2008, Pino Díaz 2008, Valenzuela 2017, Marroquín 2019), que también enfatizan la influencia intelectual de José de Acosta en los posteriores naturalistas europeos del siglo xviii, así como y la revalorización de su obra durante la época de la Ilustración.

\section{CONCLUSIONES}

La Antigüedad clásica está muy presente en la visión que los conquistadores y evangelizadores espańoles del siglo xvi proyectaron sobre el Nuevo Mundo considerando especialmente el contexto del Renacimiento europeo, que generó una revalorización de los clásicos grecolatinos a través de la difusión de sus obras y también de su gusto artístico. Uno de estos aspectos es el uso de la mitología clásica y en especial de los dioses y héroes grecorromanos, que funcionaron como un elemento comparativo para comprender las creencias religiosas de los nativos americanos y asimilarlos a sus dioses locales de acuerdo a la cercanía con sus respectivos atributos.

Esta comparación, llamada también «a efectos compensatorios» (Pino Díaz 1982), buscaba hacer más cercana la realidad remota y desconocida de un nuevo continente a un lector europeo culto (religiosos o laicos), familiarizado con la Antigüedad clásica. De esta manera, Huitzilopochtli o Quetzalcóatl podían ser definidos como «otro Hércules» o comparados con el dios Plutón. El lector de su tiempo conocía los atributos del héroe mitológico grecorromano; por tanto, podía comprender los atributos de los dioses mexicanos, lo mismo que Ometochtli, que es «otro Baco", haciendo referencia al dios del vino. Asimismo, vemos que Acosta explica en la parte correspondiente a su historia moral que a los ídolos del Perú se les atribuían diversos efectos, igual que se hiciera en la Antigüedad clásica con Mercurio, Júpiter o Minerva.

Por otra parte, a través del prisma de los clásicos, los evangelizadores buscaban demostrar que los indígenas reunían las condiciones necesarias para la conversión al cristianismo y que sus sociedades se parecían en mucho a las de la antigua y admirada civilización grecorromana, que volvía a cobrar vida con el Renacimiento en Europa. No obstante, las creencias de los nativos nunca son comparadas con la religión católica, considerada como la fe verdadera y, por tanto, incomparable y superior a cualquier otra religión. 
De alguna manera, la comparación con los clásicos también busca proporcionar elementos de comprensión a un conjunto de creencias que solía causar rechazo a los conquistadores, por actos como los sacrificios humanos o el politeísmo, pero que, gracias a los paralelos con la mitología clásica, se hacían más fáciles de comprender para el lector culto europeo, quien podría hacerse una imagen de estas culturas, pero siempre con la distorsión que significaría la aplicación de un filtro clásico tan distante cultural, temporal y geográficamente a los pueblos de las Américas. Estas comparaciones generalmente sirven a un fin: la evangelización en el Nuevo Mundo, propósito que está claramente reflejado en las obras de estos tres religiosos, y que es facilitado y legitimado en parte gracias a las comparaciones clásicas de sus escritos. Las obras de Sahagún, Mendieta y Acosta buscan informar de los propósitos misionales y también de las condiciones favorables que ofrecen estos pueblos, según la particular visión de cada uno de ellos, para la implementación de la fe católica.

Recibido: 18 de febrero de 2020; ACEptado: 30 de septiembre de 2020 


\section{BIBLIOGRAFÍA}

Acosta, J. (2008). Historia Natural y Moral de las Indias. 1590, edición crítica de Fermín del Pino Díaz. Madrid: CSIC.

Agustín. Santo, Obispo de Hipona (2007). La Ciudad de Dios, libros I-VII, introducción, traducción y notas de Rosa Marina Sáez. Madrid: Gredos.

Ballesteros, M. (1973). Vida y obra de Fray Bernardino de Sahagún. León: Institución Fray Bernardino de Sahagún.

Ballesteros, M. (1964). Códices Matritenses de la Historia General de las Cosas de la Nueva España de Fr. Bernardino de Sahagún. Madrid: Edición José Porrua Turanzas.

Brading, D. (1991). Orbe Indiano. De la monarquia católica a la República criolla, 1492-1867. Ciudad de México: Fondo de Cultura Económica.

Biersack, M. (2009). «Los Reyes Católicos y la tradición imperial romana». eHumanista, vol. 12, pp. 33-47.

Dion Casio (2004). Historia romana, libros I-XXXV (fragmentos), introducción, traducción y notas de Domingo Plácido Suárez. Madrid: Gredos.

Contreras, J., Ramos, G. y Rico, I. (1992). Diccionario de la Religión Romana. Madrid: Ediciones Clásicas.

García Jurado, F. (2016). Teoría de la tradición clásica. Conceptos, historia y métodos. Ciudad de México: Universidad Nacional Autónoma de México.

Greenblatt, S. (2011). El Giro. De cómo un manuscrito contribuyó a crear el mundo moderno. Barcelona: Crítica.

Highet, G. (1996). La Tradición Clásica, Influencias griegas y romanas en la literatura occidental. Ciudad de México: Fondo de Cultura Económica.

López Austin, A. (2001). "Fray Bernardino de Sahagún frente a los mitos indígenas». Ciencias, 60-61, pp. 6-14.

Martínez, J. (2005). «Quetzalcoatl y Heracles». EX NOVO, 1, Barcelona, 2005, pp. 43-66.

Martínez Ferrer, L. (2008). «Fray Jerónimo de Mendieta (1525-1604) y la religión mesoamericana prehispánica», en Sanz, S. y Maspero, G., editores. La natura della religione in contesto teologico, Roma: Edusc. pp. 183-205.

Martín-Esperanza, P. (2018). "Alejandro VI y las Antigüedades de Roma: coleccionismo, excavaciones y spolia». Revista Borja, Revista de L'IIEB, 6 (2017-2018), pp. 1-28.

Marroquín Arredondo, J. (2019). «La historia natural de José de Acosta y la física del globo de Alexander von Humboldt», en Marroquín, J. y Morales, A. Ciencia y traducción jesuitas en el septentrión novohispano. Nuevo Mundo Mundos Nuevos [Internet] [cited 25 abril 2020] Available from https://journals.openedition.org/nuevomundo/77934.

Mendieta, J. (1973). Historia Eclesiástica Indiana, 1604, estudio preliminar y edición de Francisco Solano y Pérez Lila. Madrid: BAE.

Phelan, John (1972). El Reino Milenario de los Franciscanos en el Nuevo Mundo, Universidad Nacional Autónoma de México: Ciudad de México D.F.

Pino Díaz, F. (1982). "Culturas clásicas y americanas en la obra del Padre Acosta», en Solano, F. y Pino Díaz, F. (eds.). América y la España del siglo XVI. Madrid: CSIC. pp. 327-363. 
Plinio el Viejo (1995). Historia Natural, libros I, II, introducción General de Guy Serbat. Madrid: Gredos.

Plinio el Viejo (1998). Historia Natural, tomo ir a, trasladada y anotada por el doctor Francisco Hernández. Ciudad de México: Visor/UNAM.

Plinio el Viejo (1998). Historia Natural, libros III-VI, traducción y notas de Antonio Fontán, Ignacio García Arribas, Encarnación del Barrio, María Luisa Arribas. Madrid: Gredos.

Plinio el Joven (2005). Cartas, introducción, traducción y notas de Julián González Fernández, Madrid: Gredos, 2005.

Reynolds, L. y Wilson, N. (1986). Copistas y filólogos. Madrid: Gredos.

Rodríguez, J.L. y Vicente Castro, F. (1986). Bernardino de Sahagún, primer antropólogo en Nueva España (siglo XVI). Salamanca: Ediciones Universidad de Salamanca.

Sahagún, B. (1989). Historia general de las cosas de la Nueva España, 1580, primera versión íntegra del texto castellano del manuscrito conocido como Códice Florentino, introducción, paleografía, glosario y notas de Alfredo López Austin y Josefina García Quintana. Madrid: Alianza Editorial.

Suetonio (1982). Los Doce Césares. Seguido de Gramáticos Ilustres, traducción del latín y notas por Jaime Arnal. Barcelona: Iberia.

TÁcito (1999). Vida de Julio Agrícola, Germania, Diálogo de los Oradores, edición de Beatriz Antón Martínez. Madrid: Gredos.

Valenzuela Matus, C. (2014). «Espiritualidad medieval y antigüedad clásica. La Historia Eclesiástica Indiana de Fray Jerónimo de Mendieta». Historias del Orbis Terrarum, 13, pp. 155-175.

Valenzuela Matus, C. (2016). Grecia y Roma en el Nuevo Mundo. La recepción de la antigüedad clásica en cronistas y evangelizadores del siglo XVI americano. Barcelona: Editorial Rubeo.

Valenzuela Matus, C. (2018). Clásicos y naturalistas jesuitas. Los antiguos en la interpretación de la naturaleza americana. Siglos XVII-XVIII. Barcelona: Editorial Rubeo. 
